\title{
A study of anemia among adolescent girls in eastern part of Nepal
}

Piush Kanodia, Mukesh Bhatta, Rupa Rajbhandari Singh, Nisha K Bhatta, Gauri Shankar Shah Department of Pediatrics and Adolescent Medicine, B.P. Koirala Institute of Health Sciences (BPKIHS), Dharan, Nepal.

\author{
Correspondence \\ Dr Piush Kanodia, \\ Department of Pediatrics and \\ Adolescent Medicine, \\ BP Koirala Institute of Health \\ Sciences, Dharan, Nepal \\ Email: \\ piushkanodia@yahoo.com
}

DOI: http://

dx.doi.org/10.3126/

jcmsn.v12i1.14683

\begin{abstract}
Background \& Objectives: Anemia is a global health problem. About $40 \%$ of the world's population suffers from anemia and adolescence is one of the most vulnerable age group. Hence the objective of the study was to determine prevalence and distribution of anemia among adolescent girls in eastern part of Nepal. Materials \& Methods: This cross sectional study was conducted in a Government School of Dharan over a period of one year. There were total 433 participants, whose clinical and demographic profile were recorded and analyzed. Hemoglobin estimation was done by using cyanmethaemoglobin method and anemia was defined as per WHO cut-off. Results: The overall prevalence of anemia was found to be $51.3 \%$. Prevalence was significantly more in pre-menarche age and undernourished girls $(\mathrm{p}<0.05)$. However factors like diet (vegetarian/nonvegetarian), worm infestation and parental education did not have a significant impact on occurrence of anemia. Conclusion: Anemia is the major health problem among adolescent girls in eastern part Nepal with high prevalence rate and nutrition is one of the leading causative factors for anemia.
\end{abstract}

Key words: Adolescent, anemia, prevalence

Citation: Kanodia P, Bhatta M, Singh RR, Bhatta NK, Shah GS. A study of anemia among adolescent girls in eastern part of Nepal. JCMS Nepal. 2016;12(1):19-22.

\section{INTRODUCTION}

The World Health Organization (WHO) defines adolescents as the population of 10 to 19 years of age. ${ }^{1}$ Adolescents learn and adopt new knowledge and practices more easily and generally these are long lasting with impact on next generation. Anemia is one of the most prevalent conditions in the world and iron deficiency is the most common cause for it among all the others. According to WHO anemia is defined as if hemoglobin less than $11 \mathrm{~g} / \mathrm{dl}$ for children below six years and less than 12 $\mathrm{g} / \mathrm{dl}$ for children more than six years of age. ${ }^{2} \mathrm{~A}$ WHO report shows that $52.0 \%$ of pregnant and around 35.0 to $40.0 \%$ of women are anemic in developing countries due to iron deficiency. ${ }^{3}$ The situation in Nepal is more severe where $36.0 \%$ age 15 to $49,42.0 \%$ pregnant and $40.0 \%$ lactating women are reported anemic4. A few studies carried out among adolescent girls in Nepal reported that prevalence ranges from 42 to $60.0 \% .^{5-8}$ Anemia among adolescents is important because (1) it covers large group of population, (2) Iron reserve subsequently helps adolescent girls for better reproductive outcome and (3) Deficiency and sufficiency of iron cause difference in performance as well as education achievement of both sexes. ${ }^{9-12}$
Adolescent period is the developmental period between the childhood and the adulthood, a time of rapid biological, cognitive and psychosocial maturation occurs. ${ }^{13,14}$ Hence the objective of the study was to determine prevalence and distribution of anemia among adolescent girls in eastern part of Nepal.

\section{MATERIALS AND METHODS}

This was a cross sectional study conducted over a period of one year ( from January 2013 to December 2013) among 433 school going adolescent girls of government schools of Dharan municipality (a small town at an altitude of $349 \mathrm{~m}$ from sea level) who were between 10-19 years of age, unmarried, non-lactating, and non-pregnant. Those with history of chronic disease, tuberculosis, chronic diarrhea, chronic renal failure, peptic ulcer, thalassemia, aplastic crisis, malignancy or those with history of severe illness requiring hospitalization within the past two weeks or those not fitting the above mentioned criteria were excluded from the study. The Adolescent age group was defined as children between 10-19 years of age. This age group was sub-divided into early adolescence (10 -13 years), mid adolescence (14-15 
years) and late adolescence (16-19 years). ${ }^{13}$ All relevant data including age, education, parental education and occupation, socioeconomic status including housing, overcrowding, drinking water, excreta disposal, Diet (vegetarian/non vegetarian), worm infestation, menstrual bleeding, etc were recorded and entered in a predesigned proforma. Physical examination was done and findings like pallor, icterus, lymphadenopathy, edema, hyperpigmentation, nail changes, petechiae, ecchymoses, eye changes or any systemic abnormalities were recorded. The height weight and BMI was measured using standard techniques.

Venous blood samples were collected in EDTA vials and sent to the central laboratory of BPKIHS. Hemoglobin estimation was done by using cyanmethaemoglobin method. Prevalence of anemia was calculated as per WHO cut-off 30 . According to WHO anemia is defined as hemoglobin less than $11 \mathrm{~g} / \mathrm{dl}$ for children below 6 years and less than $12 \mathrm{~g} / \mathrm{dl}$ for children more than 6 years of age. ${ }^{2}$ The data was analyzed using SPSS software. Student's t- test was used for comparison of data showing normal distribution, Man-Whitney $\mathrm{U}$ test for non Gaussian distribution and Chi- square test for comparison of categorical variables between anemic and non-anemic. A p value of $<0.05$ was considered significant.

Ethical issues: The study was started after the approval of the Institutional Ethical Review Board. Written Informed consent in local language was taken from the respondent, and the head of the school prior to their involving in the study.

\section{RESULT}

The study population comprised maximum number of late adolescent age group girls 242(55.9\%), followed by $153(35.3 \%)$ early adolescent age group girls and 38(8.8\%) mid adolescent age group girls. The prevalence of anemia was found to be 222 (51.3\%) among the study population. (Table1)

LVDD was found to be highly statistically significant $(p=0.002)$. Concentric LVH was detected in 22(18.33\%) patients in our study.

Anemia was found to be more prevalent in early adolescent age group girls 100(65.4\%) as compared

Table 1: Prevalence of anemia in Adolescent Girls

\begin{tabular}{ccc} 
Hemoglobin & $\mathbf{n}=\mathbf{4 3 3}$ & Percent (\%) \\
$<12 \mathrm{~g} / \mathrm{dl}$ & 222 & $51.3(\%)$ \\
$>12 \mathrm{~g} / \mathrm{dl}$ & 211 & $48.7 \%$ \\
\hline
\end{tabular}

to late and mid adolescent age group $110(45.5 \%)$ and $12(31.6 \%)$ respectively (Table.2). $65.4 \%$ of the early adolescent girls were found to be anemic as compared to $45.5 \%$ anemic girls of late adolescent age group.

Out of total study population, 23 (5.3\%) adolescent girls were vegetarian and $410(94.7 \%)$ adolescent girls were non- vegetarian girls. The Prevalence of anemia was high in vegetarian adolescent girls 16 $(69.6 \%)$. But this value was statistically not significant. $(\mathrm{P}$ value $=0.05$.) (Table.3). History of worm infestation was present in $91 \quad(21 \%)$ adolescent girls. The prevalence of anemia was almost equal in both groups, who had history of worm infestation and who had no history of worm infestation, $48 \quad(52.7 \%)$ and $174 \quad(50.9 \%)$ respectively. This value was also not statistically significant. $(\mathrm{P}$ value $=0.05$.) (Table.3).Total 153 $(35.3 \%)$ adolescent girls were in pre- menarcheal age group and $280(64.7 \%)$ adolescent girls were in menarcheal age group. All early adolescent age groups girls were in pre-menarcheal group; they had not yet attainted menarche. But the prevalence of anemia was statistically significant in premenarcheal age group girls $100(65.4 \%)$ compare to menarcheal age group girls $122(43.6 \%)$. ( $\mathrm{P}$ value is $<0.05$ ) (Table.3). Among total study population $122(28.2 \%)$ adolescent girls were under-nourished, $277(64.0 \%)$ adolescent girls had normal weight for their age and $34(7.8 \%)$ adolescent girls were overweight. The prevalence of anemia was $75.4 \%$ in under-nourished adolescent girls. This value was statistically significant. $(\mathrm{P}=0.000)$ (Table.3) There was no significant relation of parent's education with the prevalence of anemia. $(\mathrm{P}=.0 .05)$ (Table.3)

\section{DISCUSSION}

The prevalence of anemia in adolescent girls was found to be $51.3 \%$ in the present study. The various studies done in similar setting in similar geographic region, reported the prevalence of anemia among adolescent girls in the range of $40 \%$ to $60 \%$. ${ }^{14-18,22}$ The prevalence of anemia was reported in the range of four to $10.5 \%$ from developing country. ${ }^{19-21} \mathrm{But}$

Table. 2: Anemia in different age group

\begin{tabular}{cccc} 
Age group & $\mathbf{n = 4 3 3}$ & $\begin{array}{c}\text { No. anemic girls } \\
\text { Present } \\
\mathbf{( \% )}\end{array}$ & $\begin{array}{c}\text { Absent } \\
\mathbf{( \% )}\end{array}$ \\
$\begin{array}{c}\text { Early } \\
\text { adolescent }\end{array}$ & 153 & $\begin{array}{c}100 \\
(65.4 \%)\end{array}$ & $53(34.6 \%)$ \\
$\begin{array}{c}\text { Mid } \\
\text { adolescent }\end{array}$ & 38 & $12(31.6 \%)$ & $26(68.4 \%)$ \\
$\begin{array}{c}\text { Late } \\
\text { adolescent }\end{array}$ & 242 & $\begin{array}{c}110 \\
(45.5 \%)\end{array}$ & 132 \\
\hline
\end{tabular}


Table 3: Prevalence of Anemia Related to Social and Personal Characteristics

\begin{tabular}{|c|c|c|c|}
\hline Characteristics & $\begin{array}{l}\text { Anemic } \\
\mathrm{N}=222(\%)\end{array}$ & $\begin{array}{l}\text { Non } \\
\text { Anemic } \\
\text { N=211(\%) }\end{array}$ & $\begin{array}{l}P \\
\text { value }\end{array}$ \\
\hline \multicolumn{4}{|l|}{ Diet consumed } \\
\hline Vegetarian & $16(69.6)$ & $7(30.4)$ & \multirow{2}{*}{$\begin{array}{l}= \\
0.052\end{array}$} \\
\hline Non-vegetarian & $206(50.2)$ & $204(49.8)$ & \\
\hline \multicolumn{4}{|c|}{ Passage of worms } \\
\hline Yes & $48(52.7 \%)$ & $43(47.3 \%)$ & \multirow{2}{*}{0.072} \\
\hline No & $174(50.9 \%)$ & $168(49.1 \%)$ & \\
\hline \multicolumn{4}{|c|}{ Menarcheal status } \\
\hline Pre menarcheal & $100(65.4 \%)$ & $53(34.6 \%)$ & \multirow{2}{*}{0.031} \\
\hline Post menarcheal & $122(43.6 \%)$ & $158(56.4 \%)$ & \\
\hline
\end{tabular}

\begin{tabular}{llll}
\multicolumn{2}{l}{ Nutritional Status } & & \\
Undernourished & $92(75.4 \%)$ & $30(24.6 \%)$ & \\
Normal & $116(41.9 \%)$ & $161(58.1 \%)$ & 0.023 \\
Overweight & $14(41.1 \%)$ & $20(58.8 \%)$ & \\
\hline
\end{tabular}

Parental education

No formal $92(48.9 \%) \quad 96(51.1 \%)$ school education 0.015

Primary level 130(53.1\%) 115(46.9\%) and above

similar study done by Gupta et $a l,{ }^{23}$ under-nutrition was not significantly associated with the prevalence of anemia among adolescent girls, in eastern region of Nepal. Nepal Demographic \& Health Survey (NDHS, 2001) had reported that half (51\%) of the children under five years were stunted and $21 \%$ severely affected with $10 \%$ of children wasted and $1 \%$ severely wasted. ${ }^{3,4}$ Persistence of malnutrition in childhood can lead under-nutrition and anemia. We not found significant relation of anemia with diet. But various studies from India reported that, the prevalence of anemia was high in vegetarian adolescent girls in comparison to non-vegetarians adolescent girls. $^{15}$ Most of population in Nepal is non vegetarian and in our study also most of adolescent girls were non vegetarian. The prevalence of anemia was high in pre-menarcheal age group, comparative to menarcheal age group. This was statistically significant. $(\mathrm{P}=<0.05)$. Dallman and Rajaratnam et al reported that the prevalence of anemia was high in menstruating girls. ${ }^{24,-26}$. But in present study malnutrition was the main cause for anemia in pre menarcheal age group, rather than the menarche.
According to WHO parasitic infection is one of the most common cause for anemia and $60 \%$ of Nepalese are infected with one or more than one species of parasites. ${ }^{3}$ Here adolescent girls were had no symptoms for worm infestation, also we had not examined stool for worm infestation and most of the time worms were not noticed, while passing the stool. Various studies reported that there was no significant relation of parent's education with the prevalence of anemia, among adolescent girls, which is similar to our finding. ${ }^{23}$

\section{CONCLUSION}

The prevalence of anemia in adolescent girls was found to be $51.3 \%$. The prevalence of anemia was significantly high in undernourished adolescent girls, comparative to adolescent girls, who had normal body mass index. The prevalence of anemia was also significantly associated with worm infestation, diet and parent's education.

\section{RECOMMENDATION}

The improvement in the nutritional status of younger age group can prevent them from developing anemia at adolescent and early adulthood. Hence the government should focus on improvement of nutrition of children of younger age group. This might play significant role in reducing maternal morbidity, mortality and low birth weight. The study highlights a high prevalence of anemia in adolescent Nepalese girls. Further studies with a larger sample size in terrains of Nepal are needed.

\section{REFERENCES}

1. WHO. Young People's Health. A Challenge for Society. WHO Technical Report Series no 731, WHO, Geneva, Switzerland 1986.

2. Demaeyer EM. Preventing and Controlling Iron Deficiency Anemia through Primary Health Care. Geneva, World Health Organization, 1998-99.

3. WHO. The prevalence of anemia in women: A tabulation of available information. 2nd edn. Geneva. WHO 1992.

4. MOHP Nepal, New ERA and Macro International Inc. Nepal Demographic and Health Survey 2006. Kathmandu, Nepal: Ministry of Health and Population, New ERA and Macro International Inc. Kathmandu, Nepal 2007.

5. Baral KP. Iron deficiency anemia: a public health nutrition problem in Nepal Implication in Policy and Program. J Nepal Pediatr Soc 2003; 22: 29-41.

6. Rikimaru T, Joshi N, Pandey S. Prevalence of anemia and its relevant factors among High School girls of Kathmandu Valley-Nepal. Nutrition Section, Child Health Division, MOH, WHO and JICA, Kathmandu, Nepal 2003. PMID:PMC1746799.

7. Tiwari K. A study on anemia control among adolescent 
girls: Development of a school based intervention program in Kathmandu, Nepal. Doctoral thesis. Department of Food and Nutrition Faculty of Home Science, the Maharaja Sayajirao University of Baroda, Vadodara, India 2000.

8. Regmi SC, Adhikari RK. A Study on the factors influencing nutritional status of adolescent girls. New ERA, Kathmandu, Nepal 1994. PMID:8058860.

9. Lozoff B. Behavioral alteration in iron deficiency. Adv Pediatr. 1988;35:331-60. PMID:3055862.

10. Lozoff B, Jimenez E, Wolf AW. Long-term developmental outcome of infants with iron deficiency. New Engl J Med. 1991; 325: 687-94. DOI: 10.1056/ NEJM199109053251004. PMID:1870641.

11. Beard JL. Iron biology in Immune Function, Muscle Metabolism and Neuronal Functioning. J Nutr. 2001 (suppl);131:568-80.

12. Sally Grantham-McGregor, Cornelius Ani. A Review of Studies on the Effect of Iron Deficiency on Cognitive Development in Children. J Nutr. 2001(suppl);131: 64968.

13. WHO.2004.Adolescent-friendly Health Services in South -East Asia Region: Report of Regional Consultation 914 February 2004, Bali Indonesia World Health Organization/SEARO New Delhi.

14. Kaur S, Deshmukh PR, Garg BS. Epidemiological Correlates of Nutritional Anemia in Adolescent Girls of Rural Wardha. Indian Journal of Community medicine. 2006;31(4):255-8.

15. Verma M, Chhatwal J, Kaur G. Prevalence of anaemia among urban school children of Punjab. Indian Pediatrics. 1999;36:1181-6.

16. Toteja GS, Singh P, Dhillon BS, Saxena BN, Ahmed FU, Singh RP et al. Prevalence of anemia among pregnant women and adolescent girls in 16 districts of India. Food Nutr Bull. 2006 Dec;27(4):311-5. DOI: $10.1177 / 156482650602700405$. PMID: 17209473.

17. Basu S, Basu S, Hazarika R, Parmar V. Prevalence of anemia among school going adolescents of Chandigarh. Indian Pediatr. 2005 Jun;42(6):593-7. PMID:15995276.

18. Chaturvedi S, Kapil U, Gnanasekaran N, Sachdev H.P.S, Pandey R.M and Bhanti T. Nutrient intake amongst girls belonging to poor socio-economic group of rural area of Rajasthan. Indian Pediatrics. 1996;33:197-202. PMID:8772838.

19. Jackson RT, Al-Mousa Z. Iron deficiency is a more important cause of anemia than hemoglobinopathies in Kuwaiti adolescent girls. J Nutr. 2000;130:1212-6. PMID:10801921.

20. Creed-Kanashiro HM, Uribe TG, Bartoline RM, Fukumoto MN, Lopez TT, Zavaleta NM, et al. Improving dietary intake to prevent anemia in adolescent girls through community kitchens in a periurban population of Lima, Peru. J Nutr. 2000;130:459S-461S. PMID:10721928.

21. Soekarjo DD, de Pee S, Bloem MW, Tjiong R, Yip R, Schreurs WI, et al. Socio-economic status and puberty are the main factors determining anemia in adolescent girls and boys in East Jakarta, Indonesia. Eur J Clin Nutr. 2001; 55: 932-39. DOI: 10.1038/sj/ejcn/1601248. PMID:11641741.

22. Ahmed F, Khan MR, Islam M, Kabir I, Fuchs GJ. Anemia and iron deficiency among adolescent school girls in peri-urban Bangladesh. Eur J Clin Nutr. 2000; 54: 678-683. DOI: 10.1038/sj.ejcn.1601073. PMID: 11002378 .
23. Shah BK, Gupta P. Anemia in adolescent girls: a preliminary report from semi-urban Nepal. Indian Pediatr. 2002 Dec;39(12):1126-30. PMID: 12522274.

24. Dallman PR, Siimes MA, Stekel A. Iron deficiency in infancy and childhood. Am J Clin Nutr. 1980; 33: 86118. PMID: 6986756.

25. Rajaratnam J, Asolcan J.S. Prevalence of anemia among girl of rural Tamilnadu. Indian Pediatrics. 2000; 37:53253. PMID:10820547.

26. Health $\mathrm{Al}$, Skeaff $\mathrm{Cm}$, Williams $\mathrm{S}$, Gibson RS. The role of blood and diet in the etiology of mild iron deficiency in pre menopausal adult in Newzealand women. Public health nutr. 2001 April 4(2) :197-206. 